\title{
The Time Course of Phonological Encoding in Language Production: Phonological Encoding Inside a Syllable
}

\author{
Antje S. Meyer \\ Max-Planck-Institute for Psycholinguistics Nijmegen, The Netherlands
}

\begin{abstract}
Eight experiments were carried out investigating whether different parts of a syllable must be phonologically encoded in a specific order or whether they can be encoded in any order. A speech production task was used in which the subjects in each test trial had to utter one out of three or five response words as quickly as possible. In the so-called homogeneous condition these words were related in form, while in the heterogeneous condition they were unrelated in form. For monosyllabic response words shorter reaction times were obtained in the homogeneous than in the heterogeneous condition when the words had the same onset, but not when they had the same rhyme. Similarly, for disyllabic response words, the reaction times were shorter in the homogeneous than in the heterogeneous condition when the words shared only the onset of the first syllable, but not when they shared only its rhyme. Furthermore, a stronger facilitatory effect was observed when the words had the entire first syllable in common than when they only shared the onset, or the onset and the nucleus, but not the coda of the first syllable. These results suggest that syllables are phonologically encoded in two ordered steps, the first of which is dedicated to the onset and the second to the rhyme. 1991 Academic Press, Inc.
\end{abstract}

\section{INTRODUCTION}

In many theories of language production, meanings and forms of content words are represented as separate units in the mental lexicon. Consequently, lexical access to a content word is taken to involve two steps, namely the selection of a word meaning, and the retrieval of the corresponding

This paper is based on my Ph.D. dissertation submitted to the University of Nijmegen in 1988. The research was supported by a grant from the MaxPlanck-Gesellschaft zur Förderung der Wissenschaften and carried out at the Max-Planck-Institute for Psycholinguistics, Nijmegen. Preparation of this article was supported in part by a grant of the Deutsche Akademische Austauschdienst and by NIH grant NS25502-02. I thank J. Weustink for writing the software controlling the experiments; $G$. Desserjer, $H$. Franssen, and $\mathrm{H}$. Kraayeveld for helping in the selection of the stimulus materials; and K. Bock, G. Dell, L. Frazier, A. Lahiri, W. v. Lessen-Kloeke, S. Shattuck-Hufnagel, P. O'Sheaghdha, A. J. W. M. Thomassen, W. Vonk, and especially W. J. M. Levelt for helpful comments on drafts of the dissertation manuscript or this article. Correspondence concerning this article and reprint requests should be sent to $A$. S. Meyer, Max-Planck-Institute for Psycholinguistics, Postbus 310, NL-6500 AH Nijmegen, The Netherlands. sound form (see, for instance, Dell, 1986; Garrett, 1975, 1982; Levelt, 1989). The present research concerns the second of these processes which will be called phonological encoding.

Models of phonological encoding generally agree that the syllables of a word are encoded sequentially, proceeding from the beginning to the end of the word (see, for instance, Dell, 1986; MacKay, 1987; Shattuck-Hufnagel, 1979, 1983), and there is experimental evidence supporting this hypothesis (Meyer, 1990). The models differ, however, in their assumptions about the phonological encoding inside a given syllable. Shattuck-Hufnagel $(1979,1983)$, for instance, posits that this is a serial process. When a monosyllabic word is encoded, an ordered string of phonological segments is retrieved and a frame is created with three ordered slots representing the syllable constituents onset, nucleus, and coda. Then the segments are associated to the corresponding slots of the syllable frame. This is done sequentially, proceeding from the onset to the nucleus and then to the coda.

In a modification of her model, Shattuck- 
Hufnagel (1987) proposes that at some point during the phonological encoding of a phrase, its words are represented in terms of two parts, namely as word onsets and non-onset portions. This division is supported, among other things, by the observation that the segments of word onsets are far more likely to be involved in sound errors than segments in other word positions. Moreover, in sound anticipations, perseverations, and exchanges, onset segments tend to interact with each other rather than with word-internal or word-final segments (see also Garrett, 1975, 1980; Stemberger, 1983a). Shattuck-Hufnagel argues that as the metrical structure of an utterance only depends on the non-onset portions of the words, these might be integrated into the developing metrical structure before the word onsets. Thus, the phonological encoding of a monosyllabic word is still taken to be a sequential process, but the word onset is now encoded last instead of first.

By contrast, in Dell's $(1986,1988)$ model different parts of a syllable are encoded in parallel. When a monosyllabic word is encoded, activation spreads from the word node to nodes representing the syllable constituents onset and rhyme and from there to nodes representing the corresponding phonological segments. The segment nodes are marked according to their syllable positions as onset, nucleus, or coda units. If, for instance, the Dutch word bloem (flower) is encoded, activation spreads from the word node to the onset cluster [bl] and to the rhyme [u:m], and from there to the onset segments [b] and [1] and to the nucleus segment [u:] and the coda segment [m]. Simultaneously, the syllable rule is activated and creates a frame of slots corresponding to the syllable constituents onset, nucleus, and coda. After a certain time period, the activation levels of the sublexical units are inspected and the most highly activated onset, nucleus, and coda units that can be found are selected. Usually, these are the units that are being activated from the morpheme whose phonolog- ical representation is under construction. They are associated to the positions of the syllable frame, whereby they are ordered. The onset unit is linked to the onset position, the nucleus unit to the nucleus position, and the coda unit to the coda position. Though nothing hinges on the temporal order in which different positions are filled, the model assumes that they are usually filled more or less at the same time.

It should be noted that ShattuckHufnagel's and Dell's models differ not only in their assumptions about the time course of phonological encoding, but also in other, more fundamental respects. Most notably, Dell's model is a spreading activation model, whereas Shattuck-Hufnagel's is not. In Dell's model sublexical units are types; that is, there is one set of sublexical units that is shared by all words. By contrast, in Shattuck-Hufnagel's model, sublexical units are tokens, and each word has its own set of sublexical units attached to it.

The hypotheses concerning the time course of phonological encoding inside a syllable do not seem to follow of necessity from other aspects of either model. It should be possible to construe a version of Shattuck-Hufnagel's model in which the segments of a syllable are associated to their positions in parallel and a version of Dell's model in which the segments of a syllable are selected sequentially. In explaining the results of an earlier series of experiments, which investigated the temporal order of phonological encoding of successive syllables of a word (referred to as syllable experiments hereafter; see Meyer 1990), I opted for a spreading activation model very similar to Dell's. The same model is presupposed in the present paper.

This model is identical to Dell's in all major respects with one exception. According to Dell, a constant time period is devoted to the phonological encoding of each syllable within a given utterance. On this supposition the main finding of the syllable experiments is difficult to explain, which is that the subjects could produce a given word 
faster when they knew one of its syllables beforehand than when this was not the case. Therefore, I posit instead that the encoding time per syllable is variable and depends on how quickly its sublexical units become activated. Activation is taken to spread from the morpheme node to the onset, nucleus, and coda units until they have reached a certain activation threshold. Then they are selected and inserted into the slots of the syllable frame. Their activation level is instantaneously set back to zero to avoid their being immediately selected again. However, as they still receive some activation from activated higher and lower level units, their activation quickly rises again and then slowly decays.

The experiments reported below tested whether different parts of a syllable can be encoded in any order, or whether they must be encoded in a specific order, either with the onset preceding the rhyme, or with the rhyme preceding the onset. The same experimental paradigm was used as in the syllable experiments. I will first outline that paradigm and explain the predictions and then describe the method in detail.

The subject first learned three or five word pairs, for example, those listed in Table 1 . In each of the following test trials, the left-hand member of one pair was presented

TABLE 1

MATERIALS OF EXPERIMENT 1 (FXAMPI.ES)

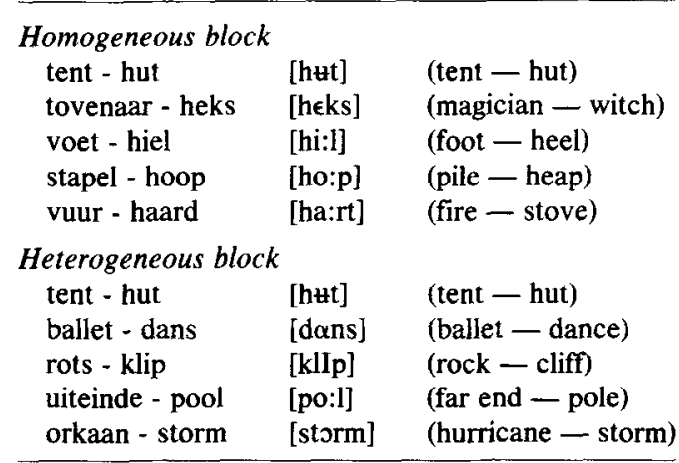

Note. The table lists the word pairs of one homogeneous and one heterogeneous test block, together with a phonetic transcription of the response words and an English translation of the stimuli. as a prompt, and the subject had to name the right-hand member of the pair, the response word, as quickly as possible. The response latency, defined as the interval between prompt onset and speech onset, was the main dependent variable. The items were tested five times each in a random order. Then the subject received performance feedback and studied the next group of word pairs, which was tested in the same way.

The materials included five sets of five word pairs each. All response words were monosyllabic. The response words within each set were systematically related in their forms. In Experiment 1 they shared the word onset and in Experiment 2 the rhyme. The segment or string of segments that the response words of a set had in common is called the implicit prime. The word pairs were tested under two conditions. In the homogeneous condition, the five word pairs that were tested together in a block of trials belonged to the same experimental set. Since there were five experimental sets, there were also five different homogeneous test blocks. In the heterogeneous condition, the word pairs of each set were distributed over five different test blocks. Thus, in each heterogeneous test block one word pair from each set was tested. As the response words of a heterogeneous block stemmed from different sets, they were not related in form.

In the syllable experiments mentioned above the mean reaction times were shorter in the homogeneous than in the heterogeneous condition when the response words shared the first syllable or the first and second syllables, but not when they shared only the second syllable. There is evidence suggesting that the effects of word-initial implicit primes were due to facilitation of the phonological encoding of the response words, rather than to facilitation of the selection of the response word meanings or to articulatory preparation. The pattern of results obtained from primes in various word positions presumably reflects the fact that 
the syllables of a word are phonologically encoded in a specific order, namely according to their sequence in the word, and that this order must be retained in preparing for the response words on the basis of implicit primes.

The present experiments were based on the expectation that phonological encoding could also be facilitated by implicit primes that included only parts of a syllable and that the effects of primes in various syllable positions would reveal whether or not there were any constraints on the temporal order of phonological encoding of different parts of a syllable. I will first lay out the predictions derived from a model in which the order of encoding different parts of a syllable is free and then turn to the predictions derived from a model in which it is fixed.

The subjects of the present experiments were expected to use the implicit primes to prepare for the utterance of the response words in a similar way as the subjects of the syllable experiments. When, for instance, the onset consonant of the response words was primed, they would probably try to keep the recurrent segment in mind during the intertrial intervals. This can be viewed as a process in which the syllable frame is created a number of times, and each time the onset position is filled by the same segment. Consequently, the activation level of that segment should be elevated above resting level when the phonological encoding of the response word begins so that it should reach the selection threshold faster than in the heterogeneous condition.

Whether or not this reduces the time necessary for the phonological encoding of the response word depends on how quickly the other segments of the word reach the selection threshold. Presumably, there is always some random variation in the resting levels of activation of the sublexical units and in the amount of activation they reccive. Therefore, they reach the selection threshold at slightly different points in time. If the primed segment is the one that would otherwise have reached the threshold most slowly, the phonological encoding of the response word should be terminated earlier than in the control condition and the reaction should be speeded. By contrast, if the primed segment would have reached the threshold first anyway, the slower segments must still be waited for. In this case, the time necessary to encode the response word and the observed reaction time should not differ from the control condition. Provided that onset, nucleus, the coda segments do not differ systematically in how fast they normally reach the selection threshold, onset primes should shorten the response latency in about one third of the trials and leave it as it was in the remaining trials. Hence, the mean reaction time for a whole block of trials should be slightly shorter in the homogeneous than in the heterogeneous condition.

On the assumption that onset, nucleus, and coda units can be selected in any order, a similar prediction can be made for the rhyme primes tested in Experiment 2. Again, the subjects should be able to prepare for the utterance of the response words on the basis of the implicit primes, and the mean reaction time should be shorter than in the heterogeneous condition. If rhymes comprise two independent processing units, mapping onto the nucleus and the coda respectively, rhyme primes should yield stronger effects than onset primes because two units instead of one are preactivated.

A model in which different parts of a syllable are encoded in a specific order makes different predictions. As mentioned, in the syllable experiments a priming effect was obtained when disyllabic response words shared the first syllable, but not when they shared the second syllable. These results were explained by assuming that the syllables of a word must be encoded in a certain temporal order, which in turn was attributed to the fact that the temporal order of their encoding determines the sequence of the syllables in the word. If a similar principle holds within syllables, if the order of 
the sublexical units within a given syllable is also governed by the temporal order of their selection, there should only be a priming effect for the unit that must be selected first. If, for instance, the onset must be selected before the rhyme, only onset primes, but not rhyme primes, should facilitate the reactions. Conversely, if the rhyme must be selected before the onset, only rhyme primes, but not onset primes, should speed the responses.

\section{EXPERIMENTS 1 AND 2}

\section{Method}

Subjects. Ten paid subjects, five women and five men, participated in each experiment. They were undergraduate students at the University of Nijmegen and native speakers of Dutch.

Stimuli. The materials of Experiment 1 consisted of five experimental sets and a practice set with five word pairs each. The response words were common monosyllabic nouns of Dutch. Within each experimental set they shared the word onset, which in three sets consisted of single consonants and in two sets of consonant clusters (see Appendix). The response words in the practice set were unrelated in form. Each response word was combined with a prompt. The prompts were semantically related to the response words with which they were coupled and unrelated to the other response words of the set.

Each experimental set represented the stimulus materials for one homogeneous test block. To construct the materials for the heterogeneous test blocks, the items were regrouped. Each heterogeneous block included one word pair from each set. The response words that were tested together in a heterogeneous block were not semantically or phonologically related to each other, and each prompt was semantically related only to the corresponding response word, but not to any other response word of the block.

Experiment 2 tested whether monosyl- labic response words could be implicitly primed by their rhymes. Again five experimental sets and a practice set with five word pairs each were created. The response words within each experimental set shared the rhyme (see Table 2). Otherwise the materials were constructed in the same way as the materials of Experiment 1.

Apparatus. The experiments were controlled by a Miro GD laboratory computer. Visual information was presented to the subject on an electronic display connected to the computer. Warning tones were played over Sennheiser HD414 headphones. The onsets of the subject's responses to the prompts were registered by a Sennheiser MD211N microphone and a voice-operated relay interfaced with the computer. The sessions were taped using a Revox A700 recorder. The experimenter sat in the same room as the subject. The information on the subject's screen, the correct response word for each trial, and the subject's reaction times were displayed to the experimenter on a second screen out of sight of the subject.

Design. The experimental design included four within-subjects variables. The 25 word pairs formed five sets, in each of which the response words shared the word onset (in Experiment 1) or the rhyme (in Experiment 2). The five sets corresponded to the levels of the first variable (sets). Each word pair was tested under the homogeneous condition (i.e., together with the other word pairs from the same set) and under the heterogeneous condition (i.e., to-

TABLE 2

Materials of Experiment 2 (Examples)

\begin{tabular}{lll}
\hline roman - boek & [bu:k] & (novel - book) \\
schilder - doek & [du:k] & (painter - canvas) \\
vis - snoek & [snu:k] & (fish - pike) \\
bocht - hoek & [hu:k] & (bend - corner) \\
heks - vloek & [vlu:k] & (witch - curse) \\
\hline
\end{tabular}

Note. The table lists the word pairs of one homogeneous test block, together with a phonetic transcription of the response words and an English translation of the stimuli. 
gether with one word pair from each of the other sets). The effect of this variable will be called context effect or, synonymously, priming effect. Within each test block, each word pair was tested five times; hence, there was a third variable, trials, with five levels. Finally, each test block was administered three times, and the fourth variable was repetitions.

In addition, there was one betweensubjects variable, groups, with two levels. The group distinction was introduced in order to control for the sequence of homogeneous and heterogeneous test blocks. The experimental session included a practice block and a series of 30 experimental test blocks, which were divided into three parts of 10 blocks cach. Within each part, each homogeneous and each heterogeneous block was administered once. In the first group of subjects, the first five blocks of each part were homogeneous and the remaining five blocks were heterogeneous. Conversely, in the second group of subjects, the first five blocks were heterogeneous and the second five were homogeneous.

The five homogeneous and the five heterogeneous blocks were administered in a different random order to each subject in each of the three parts of the experiment. The order of the word pairs within a block was also random, except that repetitions of word pairs in successive trials were avoided. Different random sequences were generated for all test blocks and subjects.

Procedure. The subjects were tested individually. After the subject had read the instructions, the practice block was administered, followed by the 30 experimental blocks. The experiment consisted of alternating presentation and test phases. In a presentation phase, the subject was given an index card, on which the word pairs for the following block were printed, and was asked to memorize the pairs until he or she knew with which response word each prompt was combined. Usually, it took the subject no longer than about two minutes to learn the five word pairs of a block. By the fifth test block, the subject had studied all items, but throughout the entire experiment a list of the relevant word pairs was presented prior to each test block so that the subject was always informed about the upcoming items.

As soon as the subject indicated that he or she had sufficiently studied the word pairs, the experimenter started the test phase. A test trial had the following structure: First, the subject heard a high warning tone $(1000 \mathrm{~Hz})$ and simultaneously saw two horizontal fixation bars marking the left and right margins of the field where the prompt would be displayed shortly afterwards. The bars appeared in the same locations on all trials, regardless of the length of the prompts. The tone and the fixation bars were displayed for $200 \mathrm{~ms}$ and were followed by a $600-\mathrm{ms}$ pause. Then the prompt was presented for $150 \mathrm{~ms}$, and the subject said the response word as quickly as possible. The speech onset was detected by the voice key, and the reaction time, measured from prompt onset, was computed and written into a data file. The prompt was followed by a blank interval of $1050 \mathrm{~ms}$. Then the next trial began. If the subject failed to react within $1000 \mathrm{~ms}$ after prompt onset, a low tone $(500 \mathrm{~Hz})$ was played for $200 \mathrm{~ms}$, and $200 \mathrm{~ms}$ after its offset the next trial began. The subject had been instructed to avoid this tone by reacting quickly enough.

The experimenter monitored the responses and marked wrong and missing responses in the data file. The mean reaction time, the numbers of wrong and missing responses, and the number of responses with latencies longer than $1000 \mathrm{~ms}$ were transformed into point scores, which were displayed to the subject at the end of each block of test trials. In order to keep track of his or her performance, the subject entered the total number of points earned in each block into a form.

Data analyses. On the basis of the taped performance record and the data files created during the experiment, correct re- 
sponses and errors were identified. There were five kinds of errors. First, subjects failed to respond (missing responses); second, they responded with latencies longer than $1000 \mathrm{~ms}$ (slow responses); third, they used wrong response words (wrong responses); fourth, they stuttered or repaired their utterances before completing a response word (disfluencies); and, fifth, they began their utterances with clicking or smacking non-speech sounds produced by the lips or the tongue (mouth clicks). The category of wrong responses includes cases where subjects first said wrong response words and then corrected themselves. More than $90 \%$ of the wrong responses were confusions among the response words of the current test block. The category of disfluencies includes speech errors resulting in non-words, which were usually blends of two response words of the current test block.

Across Experiments 1 through 8, the mean error rate per experiment was $6.29 \%$; $9.66 \%$ of the errors were missing responses, $16.52 \%$ slow responses, $10.57 \%$ wrong responses, $36.34 \%$ disfluencies, and $26.9 \%$ mouth clicks. In all experiments, the error rate was higher in the first than in the following repetitions; $46.91 \%$ of the errors occurred during the first repetition of the test blocks, $28.92 \%$ during the second, and $24.17 \%$ during the third repetition. The distributions of errors across the homogeneous and heterogeneous conditions of the experiments were analyzed using Wilcoxon tests, the results of which are reported below.

Errors were excluded from the analyses of reaction times. In addition, the reaction times of, on average, $0.7 \%$ of the trials of each experiment were missing because the voice key was triggered by noise in the environment rather than by the subject's speech. The valid reaction times from the five word pairs of each set were combined into means per subject, context, repetition, and trial. These means were submitted to an analysis of variance with one betweensubjects variable (groups), and four within- subjects variables (sets, contexts, trials, and repetitions). Geisser-Greenhouse conservative $F$ tests were used. The generality of the findings across different materials was assessed by inspecting the patterns of results for each set of a given experiment and by replicating important conditions in several experiments with different word pairs.

The reaction times tended to decrease across the three repetitions of the test blocks and across trials within test blocks. The main effect of repetitions was significant in all experiments and the main effect of trials in three of them. The main effect of sets was significant in all experiments. The corresponding statistics are not reported here, but they can be obtained from the author.

\section{Results}

Reaction times. In Experiment 1, in which the word onsets were the implicit primes, a significant context effect of $34 \mathrm{~ms}$ was obtained (means for the homogeneous and heterogeneous conditions: $615 \mathrm{~ms}$ vs. $649 \mathrm{~ms}, F(1,8)=33.47, M S_{\mathrm{e}}=12,670, p<$ $.01)$. Thus, the subjects could produce the response words of a block faster when the words shared the onset than when this was not the case. The interaction of contexts and sets was also significant $(F(1,8)=8.26$, $M S_{\mathrm{e}}=3411, p<.05$; see Table 3). In all sets, the mean reaction time was shorter in the homogeneous than in the heterogeneous test context, but in an analysis of simple effects this difference failed to reach significance in two sets.

The interaction of groups, contexts, and repetitions was also significant $(F(1,8)=$ $\left.12.77, M S_{\mathrm{e}}=3695, p<.01\right)$. An analysis of simple effects revealed that the context effect was significant in all repetitions in both groups of subjects with the exception of the first repetition in Group 1. Similar patterns of results had been obtained in some of the syllable experiments (Meyer, 1990) and were observed again in Experiments 3, 6, 7, and 8 below. They are most likely due to 
TABLE 3

Results of Experiment 1: Mean Reaction Times, Context Effects, and Error Rates per Set

\begin{tabular}{|c|c|c|c|c|c|c|c|}
\hline \multirow[b]{2}{*}{ Set } & \multirow[b]{2}{*}{ Prime } & \multicolumn{6}{|c|}{ Statistics } \\
\hline & & RT (hom) & RT (het) & Diff & $F(1,8)$ & $\mathrm{e} \%$ (hom) & $\mathrm{e} \%$ (het) \\
\hline 1 & [d]. & 622 & 640 & 18 & 4.39 & 7.20 & 4.80 \\
\hline 2 & [h] . . & 629 & 643 & 14 & 2.58 & 7.20 & 5.47 \\
\hline 3 & {$[k 1] \ldots$} & 631 & 669 & 38 & $20.29 * *$ & 6.00 & 12.00 \\
\hline 4 & [p] . . & 621 & 659 & 38 & $19.93^{* *}$ & 3.33 & 2.67 \\
\hline 5 & [st] . . & 571 & 633 & 62 & $54.80^{* *}$ & 2.53 & 4.93 \\
\hline \multicolumn{2}{|c|}{ Mean } & 615 & 649 & 34 & & 5.33 & 5.97 \\
\hline$M S_{\mathrm{e}}$ & & & & & & & \\
\hline
\end{tabular}

Note. The table displays, for each set, the mean reaction times (ms) in the homogeneous and heterogeneous conditions (RT (hom) and RT (het)), the differences between the conditions (Diff, defined as RT (het) - RT (hom)), the $F$ values from the analysis of simple effects, and the error percentages in the homogeneous and heterogeneous conditions (e\% (hom) and $\mathrm{e} \%(\mathrm{het})) . M S_{\mathrm{e}}$ is the error term of the analysis of simple effects.

${ }^{* *} p<.01$.

the fact that the two groups of subjects differed in the order of homogeneous and heterogeneous test conditions. In the first group of subjects the word pairs were first tested under the homogeneous and then under the heterogeneous condition, whereas the reverse was true in the second group. Apparently, the repetition of the items speeded the responses. This practice effect added up to the effect of the implicit primes in Group 2 and counteracted it in Group 1. The order of the two conditions noticeably affected the reaction times only in the first part of the experiment, which explains the interaction of groups, contexts, and repetitions.

In Experiment 2, in which the implicit primes consisted of the rhymes of the response words, the mean reaction times in the homogeneous and in the heterogeneous conditions were almost identical (mean: 625 ms vs. $621 \mathrm{~ms}, F(1,8)=1.73, M S_{\mathrm{e}}=4529$; see Table 4). The interaction of contexts and groups was significant $(F(1,8)=12.20$, $\left.M S_{\mathrm{e}}=4529, p<.01\right)$. In Group 1, the mean reaction time was longer in the homogeneous than in the heterogeneous blocks, whereas the reverse was true in Group 2. This pattern of results is probably due to the practice effect discussed above, which in each group favored the test condition ad- ministered last within each of the three parts of the experiment.

Error rates. In Experiment 1, the overall error rates were about the same in the homogeneous and in the heterogeneous condition $(5.33 \%$ and $5.97 \%, z=1.01)$, and there were no marked differences between the two conditions for any of the five error types. In Experiment 2, the overall error rate was higher in the homogeneous than in the heterogeneous condition $(6.19 \%$ vs. $3.95 \%, z=1.68, p<.10$ ). Errors of all five types occurred more frequently in the homogeneous than in the heterogeneous condition, but the difference was significant only for wrong responses (41 vs. 16 cases, $z$ $=2.07, p<.05)$ and for disfluencies $(138$ vs. 95 cases, $z=2.13, p<.05$ ).

TABLE 4

Results of Experiment 2: MEAN Reaction

Times, Context EfFects, and ERror Rates PER SET

\begin{tabular}{|c|c|c|c|c|c|c|}
\hline \multirow[b]{2}{*}{ Set } & \multirow[b]{2}{*}{ Prime } & \multicolumn{5}{|c|}{ Statistics } \\
\hline & & $\begin{array}{c}\mathrm{RT} \\
\text { (hom) }\end{array}$ & $\begin{array}{c}\text { RT } \\
\text { (het) }\end{array}$ & Diff & $\begin{array}{c}\mathrm{e} \% \\
\text { (hom) }\end{array}$ & $\begin{array}{c}\mathrm{e} \% \\
\text { (het) }\end{array}$ \\
\hline $\begin{array}{l}1 \\
2 \\
3 \\
4 \\
5\end{array}$ & 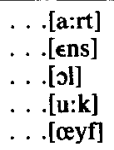 & $\begin{array}{l}625 \\
606 \\
618 \\
621 \\
656\end{array}$ & $\begin{array}{l}618 \\
604 \\
608 \\
629 \\
644\end{array}$ & $\begin{array}{r}-7 \\
-2 \\
-10 \\
8 \\
-12\end{array}$ & $\begin{array}{l}9.33 \\
5.73 \\
5.20 \\
2.93 \\
7.73\end{array}$ & $\begin{array}{l}5.20 \\
4.40 \\
3.73 \\
2.93 \\
3.47\end{array}$ \\
\hline Mean & & 625 & 621 & -4 & 6.19 & 3.95 \\
\hline
\end{tabular}


To summarize, Experiments 1 and 2 showed that the production of the response words was facilitated by implicit primes that consisted of the onsets of the response words, but not by primes that consisted of their rhymes. A possible interpretation of these findings is that the constituents of monosyllabic words are phonologically encoded in a specific order, with the onset preceding the rhyme, and that for this reason the subjects could prepare themselves for the utterance of the response words on the basis of onset primes, but not on the basis of rhyme primes. Rhyme primes barely affected the reaction times, but the distribution of errors suggests that the production of the response words was more difficult when they shared the rhyme than when this was not the case. The next two experiments tested whether the same pattern of results would be obtained for onset and rhyme of the first syllable of disyllabic response words.

\section{EXPERIMENTS 3 AND 4}

\section{Method}

Stimuli. The response words of Experiment 3 were disyllabic nouns, whose first syllable was stressed and consisted of a consonant and a long vowel (for Dutch syllabification rules see, for instance, Booij, 1981; van der Hulst, 1984). As in the first two experiments, there were five sets with five word pairs each. The response words within each set shared the word onset (see Table 5).

With one exception, these word pairs were also used in Experiment 4. For that experiment, the word pairs were regrouped in such a way that the response words

TABLE 5

MATERIALS OF EXPERIMENT 3 (EXAMPLES)

\begin{tabular}{lll}
\hline pond - kilo & ['ki:.lo:] & (pound - kilo) \\
insekt - kever & ['ke:.vor] & (insect - beetle) \\
toren - koepel & ['ku:.pal] & (tower - dome) \\
prins - koning & ['ko:.nIn] & (prince - king) \\
rivier - kade & ['ka:.də] & (river - quay)
\end{tabular}

within each set shared the rhyme of the first syllable instead of the onset (see Table 6).

\section{Results and Discussion}

Reaction times. In Experiments 3 and 4, the results of the first two experiments were replicated. In Experiment 3, where the response words in the homogeneous condition shared the word onset, there was a significant context effect of $27 \mathrm{~ms}$ (means for the homogeneous and heterogeneous conditions: $606 \mathrm{~ms}$ and $633 \mathrm{~ms}, F(1,8)=$ 95.71, $M S_{\mathrm{e}}=2979, p<.01$; see Table 7). In Experiment 4, where the response words shared the rhyme of the first syllable, the mean reaction times in the homogeneous and heterogeneous conditions differed by only $2 \mathrm{~ms}$ (means: $620 \mathrm{~ms}$ vs. $622 \mathrm{~ms}, F(1,8)$ $=0.23, M S_{\mathrm{e}}=4617$; see Table 8). In that experiment, the interaction of contexts and groups was significant $\left(F(1,8)=15.10, M S_{\mathrm{e}}\right.$ $=4617, p<.01)$. In the first group of subjects the mean reaction time was significantly longer in the homogeneous than in the heterogeneous blocks (means: $625 \mathrm{~ms}$ and $613 \mathrm{~ms}, F(1,8)=5.85, p<.05)$, whereas the reverse was true in the second group (means: $615 \mathrm{~ms}$ and $630 \mathrm{~ms}, F(1,8)=$ 9.14, $p<.05$ ).

Thus, in the experiments using monosyllabic response words and in those using disyllabic response words, primes that consisted of the word onsets, but not primes that consisted of the following rhymes speeded the production of the response words. These findings are not predicted by a model of phonological encoding in which the constituents of a syllable can be encoded in any order. Instead they support the assumption that the onset of a syllable is

TABLE 6

MATERIALS OF EXPERIMENT 4 (EXAMPLES)

\begin{tabular}{lll}
\hline melk - boter & ['bo:.tər] & (milk - butter) \\
prins - koning & ['ko:.nIn] & (prince - king) \\
bloem - lotus & ['lo:.tus] & (flower - lotus) \\
stand - pose & ['po:.zə] & (posture - pose) \\
bank - sofa & ['so:.fa:] & (bench - sofa)
\end{tabular}


TABLE 7

Results of Experiment 3: Mean Reaction TIMES, CONTEXT EFFECTS, AND ERROR RATES PER SET

\begin{tabular}{ccccccc}
\hline & & \multicolumn{5}{c}{ Statistics } \\
\cline { 3 - 7 } Set & Prime & $\begin{array}{c}\text { RT } \\
\text { (hom) }\end{array}$ & $\begin{array}{c}\text { RT } \\
\text { (het) }\end{array}$ & Diff & $\begin{array}{c}\text { e\% } \\
\text { (hom) }\end{array}$ & $\begin{array}{c}\text { e\% } \\
\text { (het) }\end{array}$ \\
\hline 1 & [b]. . & 628 & 645 & 17 & 8.00 & 4.53 \\
2 & [k]. . & 605 & 635 & 30 & 5.20 & 4.00 \\
3 & [l]. . & 598 & 621 & 23 & 7.20 & 2.67 \\
4 & [p]. . & 625 & 651 & 26 & 6.00 & 4.13 \\
5 & [s]... & 571 & 613 & 42 & 3.20 & 3.33 \\
Mean & & 606 & 633 & 27 & 5.92 & 3.73 \\
\hline
\end{tabular}

encoded before the rhyme and that for this reason the subjects could prepare themselves for the utterance of the response words on the basis of onset primes, but not on the basis of rhyme primes.

Error rates. In Experiment 3, in which disyllabic response words were primed by their word onsets, significantly more errors occurred in the homogeneous than in the heterogeneous condition (5.92\% vs. 3.73\%, $z=2.70, p<.01$ ). Errors of all types were more frequent in the homogeneous than in the heterogeneous condition, but the difference was significant only for disfluencies ( 60 vs. 35 cases, $z=1.96, p<.05$ ). Experiment 3 was the only experiment in which the context effect on error rates was significant, but higher error rates in the homogeneous than in the heterogeneous condition were also observed in other experiments, for instance, in Experiment 2. An interpretation of this finding will be proposed in the General Discussion.

TABLE 8

Results of Experiment 4: Mean Reaction Times, Context Effects, and ERror Rates PER SET

\begin{tabular}{ccccccc}
\hline & & \multicolumn{5}{c}{ Statistics } \\
\cline { 3 - 7 } Set & Prime & $\begin{array}{c}\text { RT } \\
\text { (hom) }\end{array}$ & $\begin{array}{c}\text { RT } \\
\text { (het) }\end{array}$ & Diff & $\begin{array}{c}\text { e\% } \\
\text { (hom) }\end{array}$ & $\begin{array}{c}\text { e\% } \\
\text { (het) }\end{array}$ \\
\hline 1 & $\ldots$. [a:]. . & 604 & 620 & 16 & 2.53 & 5.33 \\
2 & $\ldots$. [e:]. . & 625 & 619 & -6 & 4.67 & 4.40 \\
3 & $\ldots$. [i:]. . & 621 & 624 & 3 & 7.33 & 6.93 \\
4 & $\ldots$. .[0:]. . & 613 & 614 & 1 & 4.80 & 3.73 \\
5 & $\ldots$. [u:]. . & 637 & 630 & -7 & 7.73 & 5.87 \\
Mean & & 620 & 622 & 2 & 5.41 & 5.25 \\
\hline
\end{tabular}

In Experiment 4, in which disyllabic response words were implicitly primed by the rhyme of their first syllable, there were no marked differences between the homogeneous and heterogeneous condition, either in overall error rates $(5.41 \%$ vs. $5.25 \%, z=$ 0.53 ), or in the rates of particular types of errors.

\section{EXPERIMENTS 5 AND 6}

A possible interpretation of the results of Experiments 1 and 3 is that implicit primes consisting of word onsets speeded the phonological encoding of the response words. The priming effects could, however, also be due to articulatory preparation. When all response words of a given test block began with the same consonant or consonant cluster, the subjects could bring their speech organs into an optimal starting position to say the words instead of keeping them in a neutral position between trials, and this might have speeded the responses.

In order to test this hypothesis the next two experiments were carried out, in which disyllabic response words were either primed by their first syllable or by their first syllable plus the onset of the second syllable. If primes that include the onset of the second syllable yield stronger effects than primes that do not include it, the additional effect of the primed word-internal syllable onset is unlikely to be due to articulatory preparation, but can be ascribed to the phonological level. Then the conclusion seems warranted that the priming effect from word-initial consonants is also, at least in part, due to facilitation of the phonological encoding of the response words.

\section{Method}

Stimuli. The materials of Experiment 5 consisted of six sets with three word pairs each. All response words began in a consonant and a long vowel. The syllable boundary fell between that vowel and the following consonant. In three sets (CV-sets) the response words shared only the first syllable, and in the remaining sets (CVC-sets) 
they also shared the onset of the second syllable (see Table 9).

Experiment 6 was a replication of Experiment 5 with new materials. Again, disyllabic response words were either primed by their first syllable (CV-sets) or by that syllable plus the onset of the second syllable (CVC-sets). The response words of Experiment 5 were stressed on the first syllable, whereas those of Experiment 6 were stressed on the second syllable (see Table 10).

\section{Results and Discussion}

Reaction times. In Experiment 5, a significant context effect of $76 \mathrm{~ms}$ was obtained (means for the homogeneous and the heterogeneous conditions: $502 \mathrm{~ms}$ vs. 578 $\left.\mathrm{ms}, F(1,8)=69.36, M S_{\mathrm{e}}=59805, p<.01\right)$. The interaction of sets and contexts was also significant $\left(F(1,8)=11.21, M S_{\mathrm{e}}=\right.$ $7321, p<.05)$. As can be seen from Table 11 , the strength of the context effect varied across the sets, but it was significant in all sets. The mean priming effects were $57 \mathrm{~ms}$ for the CV-sets and $99 \mathrm{~ms}$ for the CVC-sets. Both effects were significant (means for the CV-sets: $514 \mathrm{~ms}$ and $571 \mathrm{~ms}, t(8)=8.38, p$ $<.01$; means for the CVC-sets: $490 \mathrm{~ms}$ and $586 \mathrm{~ms}, t(8)=14.31, p<.01$; as was the 39-ms difference between them $(t(8)=$ 4.16, $p<.01)^{1}$

Exactly the same pattern of results was observed in Experiment 6. The main effect of contexts was significant $(F(1,8)=55.90$, $M S_{\mathrm{e}}=4268, p<.01$ ), as was the interaction of contexts and sets $(F(1,8)=8.30$, $M S_{\mathrm{e}}=5297, p<.05$; see Table 12). The priming effect was significant for each set and for each type of sets (means for the CV-sets: $609 \mathrm{~ms}$ and $650 \mathrm{~ms}, t(8)=7.44, p$ $<.01$; means for the CVC-sets: $586 \mathrm{~ms}$ and $659 \mathrm{~ms}, t(8)=12.93, p<.01)$, and the effect was significantly stronger, by $32 \mathrm{~ms}$, in the CVC-sets than in the CV-sets $(t(8)=$ $3.88, p<.01$ ).

\footnotetext{
${ }^{1}$ One-tailed $t$ tests were used in planned comparisons.
}

TABLE 9

MATERIALS OF EXPERIMENT 5 (EXAMPLES)

\begin{tabular}{|c|c|c|}
\hline $\begin{array}{l}\text { CV-Sets } \\
\text { pond - kilo } \\
\text { steen - kiezel } \\
\text { fruit - kiwi }\end{array}$ & $\begin{array}{l}\text { ['ki:.lo:] } \\
\text { ['ki:.zəl] } \\
\text { ['ki:.vi:] }\end{array}$ & $\begin{array}{l}\text { (pound - kilo) } \\
\text { (stone - pebble) } \\
\text { (fruit - kiwi) }\end{array}$ \\
\hline $\begin{array}{l}\text { CVC-Sets } \\
\text { rogge - haver } \\
\text { schip - haven } \\
\text { valk - havik }\end{array}$ & $\begin{array}{l}\text { ['ha:.vor] } \\
\text { ['ha:.von] } \\
\text { ['ha:.vIk] }\end{array}$ & $\begin{array}{l}\text { (rye - oats) } \\
\text { (ship - harbor) } \\
\text { (falcon - hawk) }\end{array}$ \\
\hline
\end{tabular}

The effects of word onset primes in Experiments 1 and 3 could have been due to articulatory preparation or to phonological facilitation or both. By contrast, the effects of word-internal syllable onsets in Experiments 5 and 6 could not have an articulatory basis, but, most likely, stemmed from facilitation of phonological encoding. Hence, it is likely that the priming effects of the word onsets were also, at least in part, due to phonological facilitation. In fact, the effects of word-initial and word-internal syllable onsets were about equally strong, namely $31 \mathrm{~ms}$ (mean of Experiments 1 and 3) and $36 \mathrm{~ms}$ (mean of Experiments 5 and 6), respectively. Thus, articulatory preparation apparently did not play a major role in determining the strength of the priming effects.

Error rates. In Experiment 5, slightly fewer errors occurred in the homogeneous than in the heterogeneous condition $(5.79 \%$ vs. $6.9 \%, z=1.12)$. The context effect was significant for missing responses (4 vs. 26 cases, $z=2.52, p<.05$ ), but not for the remaining types of errors. In Experiment 6, wrong responses occurred significantly

TABLE 10

MATERIALS OF EXPERIMENT 6 (EXAMPLES)

$\begin{array}{lll}\begin{array}{l}\text { CV-Sets } \\ \text { komkommer - tomaat }\end{array} & \text { [to:.'ma:t] } & \text { (cucumber - tomato) } \\ \text { podium - toneel } & \text { [to:.'ne:1] } & \begin{array}{l}\text { (platform - stage) } \\ \text { geheel - totaal }\end{array} \\ \text { [to:.'ta:l] } & \text { (whole - total) } \\ \begin{array}{l}\text { CVC-Sets } \\ \text { specerij - komijn }\end{array} & \text { [ko:.'mein] } & \text { (spice - cumin) } \\ \text { grap - komiek } & \text { [ko:.'mi:k] } & \text { (joke - comic) } \\ \text { ster - komeet } & \text { [ko:.'me:t] } & \text { (star - comet) }\end{array}$


TABLE 11

Results of Experiment 5: Mean Reaction Times, Context Effects, and Error Rates per Set

\begin{tabular}{|c|c|c|c|c|c|c|c|}
\hline \multirow[b]{2}{*}{ Set } & \multirow[b]{2}{*}{ Prime } & \multicolumn{6}{|c|}{ Statistics } \\
\hline & & RT (hom) & RT (het) & Diff & $F(1,8)$ & $\mathrm{e} \%$ (hom) & e\% (het) \\
\hline \multicolumn{8}{|c|}{ CV-Sets } \\
\hline 1 & [da:.]. . . & 500 & 572 & 72 & $39.04^{* *}$ & 7.36 & 6.39 \\
\hline 2 & [ha:.]. . . & 516 & 578 & 62 & $28.98^{* *}$ & 9.58 & 8.61 \\
\hline 3 & [ki:.]. . . & 527 & 562 & 35 & $8.69^{*}$ & 6.25 & 7.92 \\
\hline Mean & & 514 & 571 & 57 & & 7.73 & 7.64 \\
\hline \multicolumn{8}{|c|}{ CVC-Sets } \\
\hline 4 & [ha:.v]. . . & 451 & 561 & 110 & $90.12^{* *}$ & 3.06 & 5.97 \\
\hline 5 & [ko:.l]. . . & 511 & 598 & 87 & $55.81^{* *}$ & 3.89 & 6.53 \\
\hline 6 & [po:.l]. . . & 508 & 599 & 91 & $61.05^{* *}$ & 4.58 & 5.97 \\
\hline \multicolumn{2}{|l|}{ Mean } & 490 & 586 & 96 & & 3.84 & 6.16 \\
\hline \multicolumn{8}{|c|}{$M S_{c}=16,069$} \\
\hline
\end{tabular}

${ }^{*} p<.05$.

$* * p<.01$.

more frequently in the homogeneous than in the heterogeneous condition ( 49 vs. 26 cases, $z=1.99, p<.05)$. The other types of errors were observed about equally frequently in the two conditions, and the overall error rates did not differ significantly from each other $(7.85 \%$ vs. $7.13 \%, z=$ 1.02).

In both experiments, the error rates for $\mathrm{CV}$-sets were about the same in the homogeneous and the heterogenous conditions (see Tables 11 and 12). In the CVC-sets of Experiment 5 significantly fewer errors occurred in the homogeneous than in the heterogeneous condition ( $3.84 \%$ vs. $6.16 \%, z$ $=2.55, p<.05$ ), whereas in the CVC-sets of Experiment 6 slightly more errors were observed in the homogeneous than in the heterogeneous condition (8.56\% vs. $6.95 \%$, $z=1.84, p<.10$ ).

\section{EXPERIMENTS 7 AND 8}

The results of Experiments 1 to 6 can be explained by assuming that syllables are encoded in at least two steps, dedicated to the onset and the rhyme, respectively. However, it is possible that more steps are necessary to encode complex syllables. On the basis of speech error evidence, it has been proposed that the sublexical units, out of which word forms are created, are seg- ments and segment sequences that map onto the syllable constituents onset, nucleus, and coda (see, for instance, Dell, 1986; Shattuck-Hufnagel, 1979, 1983). Thus, syllables might be encoded in three steps, in each of which one of these sublexical units is selected. This hypothesis was tested in Experiments 7 and 8. Disyllabic response words were used whose first syllable included an onset consonant, a short vowel, and a coda consonant (CVCresponse words hereafter). Three types of implicit primes were tested, namely wordonset consonants (C-primes), word-initial $\mathrm{CV}$-groups (CV-primes), and the complete first syllables of the response words (CVCprimes). If the units that are encoded in successive steps are onset, nucleus, and coda, the strength of the priming effect should increase from $\mathrm{C}$ - to $\mathrm{CV}$-primes and from $\mathrm{CV}$ to CVC-primes. By contrast, if the units of phonological encoding are onsets and rhymes, CVC-primes should yield stronger effects than C-primes, but CV-primes might not be more efficient than C-primes because the vowels do not correspond to the complete rhymes.

\section{Method}

Stimuli. As only two types of sets could be included in a single experiment, two ex- 
TABLE 12

Results of Experiment 6: Mean Reaction Times, Context Effects, and Error Rates per Set

\begin{tabular}{|c|c|c|c|c|c|c|c|}
\hline \multirow[b]{2}{*}{ Set } & \multirow[b]{2}{*}{ Prime } & \multicolumn{6}{|c|}{ Statistics } \\
\hline & & RT (hom) & RT (het) & Diff & $F(1,8)$ & $\mathrm{e} \%$ (hom) & e\% (het) \\
\hline \multicolumn{8}{|c|}{ CV-Sets } \\
\hline 1 & [bu:.]. . . & 615 & 644 & 29 & $8.79^{*}$ & 9.31 & 9.72 \\
\hline 2 & [ko:.]. . . & 610 & 661 & 51 & $27.20^{* *}$ & 6.67 & 8.47 \\
\hline 3 & [to:.]. . . & 602 & 647 & 45 & $21.18^{* *}$ & 5.42 & 3.75 \\
\hline Mean & & 609 & 650 & 41 & & 7.13 & 7.31 \\
\hline \multicolumn{8}{|c|}{ CVC-Sets } \\
\hline 4 & [ba:.r]. . & 572 & 642 & 70 & $51.24^{* *}$ & 7.08 & 8.89 \\
\hline 5 & [ko:.m]. . . & 595 & 665 & 70 & $51.24^{* *}$ & 13.47 & 5.56 \\
\hline 6 & [ta:. $\mathbf{b}] .$. & 591 & 670 & 79 & $55.72^{* *}$ & 5.14 & 6.39 \\
\hline Mean & & 586 & 659 & 73 & & 8.56 & 6.95 \\
\hline$M S_{\mathrm{e}}=$ & & & & & & & \\
\hline
\end{tabular}

periments were run in order to test the effects of C-, CV-, and CVC-primes. In Experiment 7 , there were three sets in which the response words shared the word onset consonant (C-sets) and three sets in which they shared the word-initial CV-group (CVsets). The CV-sets were also tested in Experiment 8 , together with three sets in which the response words shared the entire first CVC-syllable (CVC-sets; see Table 13).

\section{Results}

Reaction times. In both experiments, the context effect was significant (means for the homogeneous and heterogeneous conditions of Experiment 7: $571 \mathrm{~ms}$ vs. $597 \mathrm{~ms}$, $F(1,8)=20.02, M S_{\mathrm{e}}=23,340, p<.01$; means for the homogeneous and heterogeneous conditions of Experiment 8: $581 \mathrm{~ms}$ vs. $628 \mathrm{~ms}, F(1,8)=34.01, M S_{\mathrm{e}}=45,703$, $p<.01$; see Tables 14 and 15). The effect was significant for all types of sets that were tested. The effects for the C- and CVsets of Experiment 7 were about equal in strength, namely $28 \mathrm{~ms}$ and $23 \mathrm{~ms}$, respectively (means for the C-sets: $581 \mathrm{~ms}$ and 609 ms, $t(8)=5.34, p<.01$; means for the CV-sets: $562 \mathrm{~ms}$ and $585 \mathrm{~ms}, t(8)=4.20, p$ $<.01)$. In Experiment 8 , the priming effects

TABLE 13

Materials of ExPERIMENTS 7 AND 8 (EXamples)

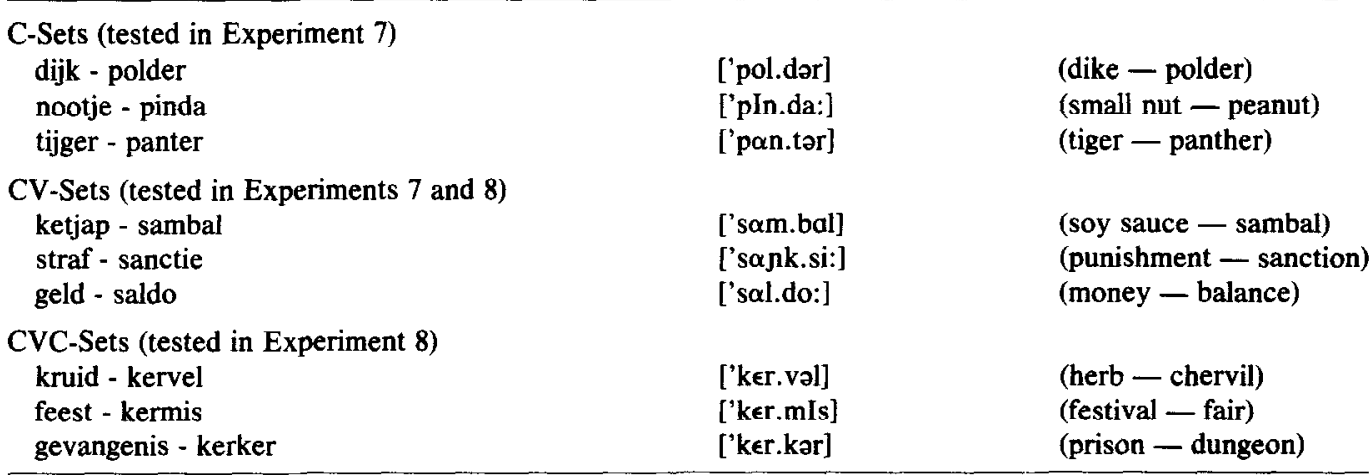


TABLE 14

Results of Experiment 7: Mean Reaction Times, Context EFFects, and ERror Rates PER SET

\begin{tabular}{|c|c|c|c|c|c|c|}
\hline \multirow[b]{2}{*}{ Set } & \multirow[b]{2}{*}{ Prime } & \multirow[b]{2}{*}{$\begin{array}{c}\text { RT } \\
\text { (hom) }\end{array}$} & \multicolumn{3}{|c|}{ Statistics } & \multirow[b]{2}{*}{$\begin{array}{l}\mathrm{e} \% \\
\text { (het) }\end{array}$} \\
\hline & & & $\begin{array}{c}\text { RT } \\
\text { (het) }\end{array}$ & Diff & $\begin{array}{c}\mathbf{e \%} \\
\text { (hom) }\end{array}$ & \\
\hline \multicolumn{7}{|c|}{ C-Sets } \\
\hline 1 & {$[p]$. } & 583 & 610 & 27 & 5.42 & 7.64 \\
\hline 2 & [s]. & 580 & 625 & 45 & 4.31 & 9.17 \\
\hline 3 & {$[\mathbf{t}]$.} & 578 & 591 & 13 & 7.50 & 4.86 \\
\hline Mear & & 581 & 609 & 28 & 5.74 & 7.22 \\
\hline \multicolumn{7}{|c|}{ CV-Sets } \\
\hline 4 & {$[\mathrm{~d} \epsilon] . .$.} & 551 & 576 & 25 & 6.39 & 5.56 \\
\hline 5 & [ka]. & 589 & 596 & 7 & 10.00 & 8.61 \\
\hline 6 & {$[s \alpha]$.} & 546 & 582 & 36 & 7.92 & 6.53 \\
\hline Mear & & 562 & 585 & 23 & 8.10 & 6.90 \\
\hline
\end{tabular}

were $34 \mathrm{~ms}$ for the $\mathrm{CV}$-sets and $59 \mathrm{~ms}$ for the CVC-sets (means for the CV-sets: 593 $\mathrm{ms}$ and $627 \mathrm{~ms}, t(8)=5.25, p<.01$; means for the CVC-sets: $569 \mathrm{~ms}$ vs. $628 \mathrm{~ms}, t(8)=$ $9.81, p<.01)$. The 25 -ms difference in the strength of the effects between the two types of sets was significant $(t(8)=2.72, p$ $<.01)$.

The main results of Experiments 7 and 8 are summarized in Fig. 1, together with the findings of Experiments 3 and 5. The response words of Experiments 7 and 8 began with stressed CVC-syllables, whereas those of Experiments 3 and 5 began with stressed CV-syllables. These two types of response words are called CV- and CVCresponse words, respectively. Three types of implicit primes were tested, namely word onset consonants (C-primes), wordinitial CV-groups (CV-primes), and wordinitial CVC-groups (CVC-primes). As the figure shows, CV- and CVC-response words were primed equally efficiently by their word-onset consonants; the priming effects were $27 \mathrm{~ms}$ and $28 \mathrm{~ms}$, respectively. The remaining two types of primes yielded substantially stronger effects for CV-than for CVC-response words. The figure also shows that CV-response words were primed as efficiently by $\mathrm{CV}$-primes as CVC-response words by CVC-primes. In other words, a constant priming effect, of approximately $58 \mathrm{~ms}$, was obtained when the response words were primed by their first syllable, regardless of the number of segments the syllable included.

Comparable results had been obtained in a pilot study in which CV- and CVCresponse words were primed by their first syllable. The priming effect was significant (means for the homogeneous and heterogeneous conditions: $570 \mathrm{~ms}$ and $600 \mathrm{~ms}$, $\left.F(1,8)=6.43, M S_{\mathrm{e}}=99,129, p<.05\right)$ and equally pronounced for both types of response words (means priming effects: 29

TABLE 15

Results of Experiment 8: Mean Reaction Times, Context Effects, and Error Rates per Set

\begin{tabular}{|c|c|c|c|c|c|c|}
\hline \multirow[b]{2}{*}{ Set } & \multirow[b]{2}{*}{ Prime } & \multicolumn{5}{|c|}{ Statistics } \\
\hline & & RT (hom) & RT (het) & Diff & e\% (hom) & $\mathrm{e} \%$ (het) \\
\hline \multicolumn{7}{|c|}{$\overline{C V}$-Sets } \\
\hline 1 & {$[\mathrm{~d} \epsilon] \ldots$} & 563 & 604 & 41 & 8.19 & 4.58 \\
\hline 2 & {$[k \alpha] \ldots$} & 611 & 638 & 27 & 10.42 & 9.44 \\
\hline 3 & {$[s \alpha] \ldots$} & 605 & 639 & 34 & 15.69 & 6.94 \\
\hline Mean & & 593 & 627 & 34 & 11.43 & 6.99 \\
\hline \multicolumn{7}{|c|}{ CVC-sets } \\
\hline 4 & [hol.]. . . & 559 & 637 & 78 & 7.92 & 8.33 \\
\hline 5 & [ker.]. . . & 563 & 626 & 63 & 5.42 & 5.56 \\
\hline 6 & [mor.]. . . & 585 & 621 & 36 & 6.39 & 8.61 \\
\hline Mean & & 569 & 628 & 59 & 6.58 & 7.50 \\
\hline
\end{tabular}




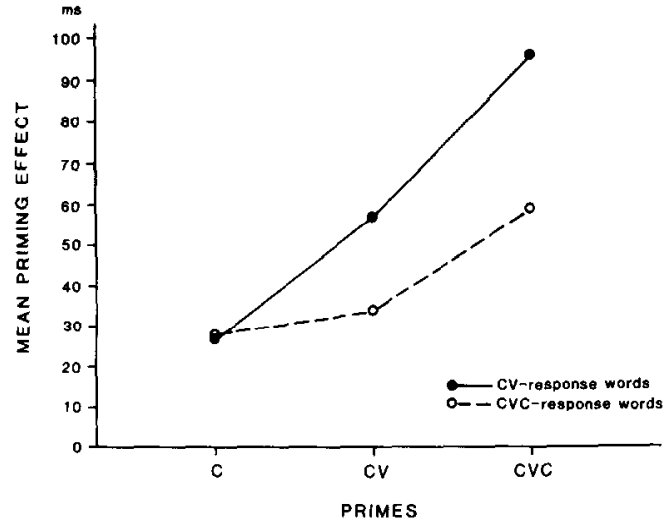

FIG. 1. Effects (ms) of primes including the word onset (C-primes), the word-initial CV-group (CVprimes), and the word-initial CVC-group (CVCprimes) for response words beginning with $\mathrm{CV}$ syllables ( $\mathrm{CV}$-response words) and $\mathrm{CVC}$-syllables (CVC-response words).

ms and $31 \mathrm{~ms}$ ). Thus, both CV-and CVCsyllables are apparently encoded in two steps each, one dedicated to the onset and one to the rhyme.

Error rates. In Experiment 7, the overall error rates in the homogeneous and heterogeneous condition were about the same $(6.92 \%$ vs. $7.06 \%, z=0.10)$, and no significant differences between the two conditions were obtained for any of the five types of errors. In Experiment 8, the error rate was slightly higher in the homogeneous than in the heterogeneous condition $(9.0 \%$ vs. $7.25 \%, z=1.63)$. As Table 15 shows, this difference is due to the error distribution in the CV-sets. Disfluencies were more frequent in the homogeneous than in the heterogeneous condition ( 207 vs. 87 cases, $z=2.67, p<.01)$. This tendency was more pronounced in the $\mathrm{CV}$-sets (137 vs. 45 cases) than in the CVC-sets (70 vs. 42 cases). In both types of sets, missing responses were less frequent in the homogeneous than in the heterogeneous condition (37 vs. 64 cases across all sets, $z=2.03, p$ $<.05)$.

\section{General Discussion}

The experiments reported above studied the effects of various types of implicit primes on the production of mono- and disyllabic response words. The two main findings were, first, that priming effects on the reaction times were only found when the primes included the onsets of the response words, and second, that the strength of the effects increased with the length of the primes, defined in terms of the number of primed onsets and rhymes. Priming effects of about equal strength were obtained from word-initial and wordinternal syllable onsets, which suggests that the implicit primes facilitated the phonological encoding of the response words rather than their articulation.

In Dell's (1986) model of phonological encoding, successive syllables of a word must be encoded in a specific order, namely proceeding from the beginning of the word to the end, because the temporal order of their encoding determines the sequence of the syllables in the phonological representation and thereby in the utterance. The results of an earlier series of experiments (Meyer, 1990) support this assumption. The present results suggest that onset and rhyme of a syllable are likewise selected in a particular order; possibly because their sequence in the phonological representation is also determined by the temporal order of their selection. Thus, the same ordering principle might hold between and within syllables. In Dell's model, syllables are important processing units, determining which parts of a word are encoded at about the same time and which parts are encoded at different times. The data presented above suggest that the units that are encoded sequentially are not complete syllables, but the syllable constituents onset and rhyme.

According to this proposal, the sublexical units of a word could be selected and ordered in the following way. Activation spreads in parallel from the word to a set of syllable onsets and rhymes. If, for instance, the Dutch word ['pon.tor] (panther) is encoded, four sublexical units are activated, namely $[\mathrm{p}],[\alpha \mathrm{n}],[\mathrm{t}]$, and [or]. At any given 
moment, one of these units is activated particularly strongly. In the example this is initially the unit [p]. It reaches the selection threshold first and therefore becomes the first part of the word. After being selected, its activation level drops to zero, and then the next unit, $[\alpha n]$ in the example, is activated most strongly. It is selected next and becomes the next part of the word, and so on, until the end of the word is reached.

When the response words in a homogeneous block of an implicit priming experiment had the same word onset, the subjects probably tried to keep the recurrent consonant or consonant cluster in mind between trials. Presumably, the onset consonant or cluster was activated and selected repeatedly so that its activation levcl was alrcady elevated above its usual resting level when the encoding of a response word began. Therefore, the onset unit could be selected more rapidly, and the phonological encoding of the response word took less time than in the heterogeneous condition, in which the response words had different onsets. When the response words shared the rhyme of the first syllable, the subjects could not prepare themselves between trials in the same way. If at the beginning of the phonological encoding of a given response word the rhyme of its first syllable were more highly activated than the word onset, the rhyme would reach the selection threshold before the onset and would become the first part of the word, which would, of course, be wrong.

It should be noted that the segments of successive syllable constituents are taken to be selected in a particular order. A stronger claim would be that the segments of one syllable constituent only begin to be activated after those of the preceding constituent have been selected (see MacKay, 1987, for a discussion of the distinction between activation and selection of units). There is speech error evidence suggesting that this latter supposition is probably wrong. For instance, speakers sometimes anticipate segments that were meant to appear later in the utterance, or they exchange segments of two words (as, for instance, in heft lemisphere instead of left hemisphere, see Fromkin, 1973, Appendix), which indicates that segments of several words must be activated simultaneously. Also, sound anticipations and exchanges are more likely to involve two segments that are followed by identical segments (as in the above example) than two segments that are followed by different segments. The identical segment need not be a direct neighbor of the interacting segments (see Dell, 1984, 1988; MacKay, 1970, for a discussion of this repeated phoneme effect). Thus, at the moment of the error at least some of the segments following the interacting ones must also be activated.

In five of the eight experiments reported above, more errors were observed in the homogeneous than in the heterogeneous condition. Across all experiments, $53 \%$ of the errors happened in the homogeneous condition. This trend was mainly due to the distribution of wrong and disfluent responses; $58 \%$ of the wrong and $56 \%$ of the disfluent responses occurred in the homogeneous condition. The remaining types of errors were about equally frequent in the two conditions. Thus, whereas the results of the reaction time analyses show that the production of the response words was facilitated by certain types of implicit primes, the results of the error analyses suggest that the production of the response words was more difficult in the homogeneous than in the heterogeneous condition.

A noteworthy difference between the context effect on reaction times and the effect on error rates is that only the former effect was governed by the nature of the implicit primes. Context effects on the reaction times were obtained only from primes that included the word onsets, and the strength of the effects was determined by the length of the primes. By contrast, whether or not the error rate for a given set was higher in the homogeneous than in the heterogeneous condition depended neither 
on the word position, nor on the length of the implicit prime. For example, the only significant effect for the error rates $(5.92 \%$ vs. 3.73\%) was obtained in Experiment 3, in which the implicit primes were the word onsets. In Experiment 1, however, in which the same type of implicit prime was used, the error rates in the homogeneous and heterogeneous condition were about the same (5.33\% vs. $5.97 \%$ ), and in the C-sets of Experiment 7 the error rate was lower in the homogeneous than in the heterogeneous condition (5.74\% vs. $7.22 \%)$. Similarly, a relatively large difference in error rates (6.19\% vs. $3.95 \%$ ) was observed in Experiment 2, in which monosyllabic response words were primed by their rhymes; but again, this result was not replicated in Experiment 4 (error rates: $5.41 \%$ vs. $5.25 \%$ ), in which the implicit primes were the rhymes of the first syllable of disyllabic response words. By contrast, a very regular pattern of results was obtained in the analyses of reaction times. In Experiments 1, 3, and 7 , in which the response words were implicitly primed by their word onsets, the priming effects were $34 \mathrm{~ms}, 27 \mathrm{~ms}$, and 28 ms, respectively. In Experiments 2 and 4, in which rhyme primes were tested, the reaction times in the homogeneous and heterogeneous conditions were practically identical (means for Experiment 2: $625 \mathrm{~ms}$ and $621 \mathrm{~ms}$; means for Experiment 4: $620 \mathrm{~ms}$ and $622 \mathrm{~ms}$ ).

The difference between the effects on reaction times and error rates in how systematically they were affected by the nature of the implicit primes might indicate that the effects arose at different moments during the preparation of the utterances. The reaction time effect most likely occurred during the creation of the phonological representations of the response words, whereas the error rate effect probably originated during the selection of the response words. When a given prompt was read, the corresponding response word became activated and passed some of its activation on to its phonological segments. According to the model of phonological encoding assumed here, the links among the units in the mental lexicon are bidirectional (see, Dell, 1986). Hence, the activated segments fed some of their activation back to the target word; but in the homogeneous condition, in which the response words had certain segments in common, the other response words of the test block also received some activation from the activated segments. This might have rendered the selection of the correct response word more difficult than in the heterogeneous condition, where unintended response words were not activated from the segmental level. The difficulty of lexical selection depended, however, on a number of additional factors, such as, for instance the strength of the associations between prompts and response words, the relative frequencies of the words, and the semantic relationships among them. Presumably the error rate for a given set was higher in the homogeneous than in the heterogeneous condition only if several of these factors conspired in making the selection of the response words particularly difficult. For this reason, errors were slightly more likely in the homogeneous than in the heterogeneous condition, but a significant difference in error rates was not obtained for each and every set.

The assumption that the selection of the response words was more difficult in the homogeneous than in the heterogeneous condition explains why wrong responses, which were practically always confusions among the response words of a given set, were more likely in the former than in the latter condition. It also explains the distribution of sound errors. Across all experiments a total of 35 sound errors were observed, 21 of which were blends of two response words (such as, for instance, "salbal," created out of "sambal" and "saldo"). Blends can be taken to originate at the level of lexical selection. Instead of selecting a single word unit for further processing, the formulator chooses two units, which are both phonologically encoded and 
then fused (see, for instance, Garrett, 1980; Levelt, 1989). Interestingly, with one exception all blends of the present experiments happened in the homogeneous condition. This supports the assumption that the selection of the response words was more difficult in the homogenous than in the heterogeneous condition. The remaining 14 sound errors were word-internal reversals of segments, anticipations, deletions, and additions of segments, which are usually taken to arise during the phonological encoding or the articulation of utterances. These errors were observed more often ( 9 out of 14 times) in the heterogeneous than in the homogeneous condition.

Unfortunately, the origin of repairs and stuttered responses cannot be unambiguously determined. Stuttering can be due to an articulatory problem, or it can be a manifestation of a covert repair (Levelt, 1989). In the latter case, the speaker recognizes an error in the utterance plan and interrupts himself or herself before the unintended part of the utterance has been reached. It is unknown which types of errors the subjects in the implicit priming experiments repaired overtly or covertly most frequently. At least in some cases they probably selected a wrong response word, began to articulate it and then interrupted themselves. But errors could, of course, also arise during the creation of the phonological representations. The creation of those parts of the wordforms that constituted the implicit primes should be both faster and less error-prone in the homogeneous than in the heterogeneous condition. The construction of the remaining parts of the wordforms might, however, be more difficult in the homogeneous condition. If, as was argued above, in the homogenous condition all response words of the test block received some activation from the segments they had in common, and if the word units passed some of their activation on to all of their segments, the competition among the segments that were not included in the implicit primes might be enhanced, which might have ren- dered the encoding of the unprimed parts of the words more difficult than in the heterogeneous condition.

To summarize, whether or not the mean response latency for a given set of word pairs was shorter in the homogeneous than in the heterogeneous condition and how strong the priming effect was depended on the word position and the length of the implicit prime. Errors were slightly more frequent in the homogeneous than in the heterogeneous condition, but the error rates were not systematically affected by the nature of the implicit primes. It was argued that the error rate tended to be higher in the homogeneous than in the heterogeneous condition because the selection of the response words or the phonological encoding of the unprimed parts of the words was more difficult in the former than in the latter condition. At any rate, the distribution of the errors does not seem to challenge the main conclusion drawn from the analyses of reaction times, which is that the sublexical units of a word must be selected in a particular order, namely according to their sequence in the word.

It was proposed above that the parts of a word that are encoded in separate steps are the syllable constituents onset and rhyme. This claim might, however, be too general. Experiment 8 showed that certain Dutch rhymes are coherent units of phonological encoding. It would be premature to conclude that this is true for all rhymes of all languages. In fact, it is not even certain that other Dutch VC-rhymes are equally coherent. For English, there is evidence that highly sonorous postvocalic segments, such as the liquids / $/$ and $/ r /$, are more closely associated to the preceding vowels than less sonorous consonants (see MacKay, 1972; Shattuck-Hufnagel, 1986; Stemberger, 1983b; Treiman, 1984). Whether this also holds for Dutch remains to be seen. At any rate, 11 out of the 18 word-initial CVC-syllables of Experiment 8 ended in liquids and 5 in nasals. The experimental results might have been different if 
all syllables had ended in stops. Dutch also has more complex rhymes, comprising a short vowel and a consonant cluster (like, for instance, in [hond] (dog)), or a long vowel or diphthong and a consonant or consonant cluster (like in [di:r] (animal) or [be:st] (beast)). Such rhymes might be coherent units of phonological encoding, or they might break up into a nucleus and a coda. Finally, the current findings obviously do not allow for any conclusions concerning the coherence of onset clusters.

To sum up, it is proposed that the units of phonological encoding are neither complete syllables, nor necessarily individual phonological segments, but the segments and segment sequences that map onto certain syllable constituents. Whether the relevant syllable constituents are always onsets and rhymes or whether certain onsets or rhymes break up into smaller constituents remains to be established. This view does not exclude the possibility that word forms are represented in more than one way. The present data suggest that there is one level of representation that is created by selecting and combining segments and segment sequences corresponding to syllable constituents. There might, however, be other levels whose processing units are complete syllables or individuals phonological segments or features.

The proposal that syllable constituents are important units of phonological encoding is, of course, not new, but has been made many times on the basis of speech error analyses. It has often been noted that the error units (i.e., the unintended parts in speech errors) tend to correspond to complete syllable constituents of the target words (see Dell, 1986; MacKay, 1970, 1972; Shattuck-Hufnagel, 1979, 1983; Stemberger, 1983b). This has been demonstrated most clearly for syllable onsets, which are involved in sound errors far more frequently than other constituents (see, for instance, Shattuck-Hufnagel, 1983, 1987). Whether rhymes are single processing units or comprise two units (a nucleus and a coda) is difficult to decide, mainly because errors involving these syllable constituents are fairly rare. The available evidence is usually taken to favor the assumption that nucleus and coda are separate processing units (see, Dell, 1986; Shattuck-Hufnagel, 1979, 1983; Stemberger, 1983b). The present results support the customary assumption that the segments of certain syllable constituents are selected simultaneously. In addition, they suggest that the segments of successive constituents are selected at different times, which was not obvious from the speech error evidence.

Finally, the conclusion that onsets and rhymes are encoded sequentially sheds a new light on the association of segments and syllables. In Dell's (1986) model, the main function of this process is to order the segments, which are activated and selected in parallel. If, however, the order of the sublexical units is determined by the temporal order of their selection, their association to the slots of syllable frames cannot be viewed as an ordering process, and the question arises of why this process takes place at all. On these grounds, one could argue that the notion of a syllable frame could be abandoned.

However, the results of the implicit priming experiments and the speech error evidence mentioned above support the notion of syllable constituents. In addition, a very robust finding of speech error analyses is that misplaced segments tend to move from their target positions to corresponding positions in new syllables rather than to different positions. Onset segments typically move to new onset positions, nucleus segments to new nucleus positions, and coda segments to new coda positions (see, for instance, Boomer \& Laver, 1968; Fromkin, 1971; Garrett, 1975, 1980; MacKay, 1970; Nooteboom, 1969; Shattuck-Hufnagel, 1979,1983 , 1987; but see, for counterevidence, Abd-El Jawad \& Abu-Salim, 1987). And there is, of course, strong linguistic evidence supporting the notion of the syllable (see, for instance, Fudge, 1969; 
Hayes, 1981; Hyman, 1985; Nespor \& Vogel, 1986; Selkirk, 1984). For these reasons, it seems inappropriate to eliminate the syllable from a theory of phonological encoding. The syllable probably does not play a role in ordering the segments of a word, but it might be a unit of an independent level of representation, as has been proposed on linguistic grounds (see, for instance, Goldsmith, 1986; Halle \& Vergnaud, 1980). Thus, following Dell (1986), ShattuckHufnagel $(1979,1983)$, and others, I assume that phonological encoding involves the selection of phonological segments and segment sequences, the creation of syllable frames, and the insertion of the segments and sequences into the slots of the syllable frames. The association of phonological segments and syllables can be viewed as the integration of two complete and fully ordered representations of different aspects of word forms.

\section{APPENDIX \\ RESPONSE WORDS OF EXPERIMENTS 1 Through 8}

Experiment I

Set 1: dans, dop, deugd, doek, dier

Set 2: hut, heks, hiel, hoop, haard

Set 3: klip, kleur, klomp, kleed, klant

Set 4: pool, poes, paard, pink, pen

Set 5: storm, stad, steek, stijl, stoep

Experiment 2

Set 1: haard, paard, kaart, waard, baard

Set 2: lens, grens, pens, mens, wens

Set 3: wol, stol, hol, bol, mol

Set 4: boek, doek, snoek, hoek, vloek

Set 5: duif, kluif, ruif, schuif, huif

Experiment 3

Set 1: bezem, boeking, boter, basis, bivak

Set 2: kilo, kever, koepel, koning, kade

Set 3: larie, lire, lepra, loeder, lotus

Set 4: pose, pasen, python, pekel, poema

Set 5: suiker, sofa, sabel, sinas, serie

\section{Experiment 4}

Set 1: basis, kade, larie, pasen, sabel

Set 2: bezem, kever, lepra, pekel, serie

Set 3: bivak, kilo, lire, python, sinas

Set 4: boter, koning, lotus, pose, sofa

Set 5: bocking, koepel, loeder, poema, woede

\section{Experiment 5}

CV-Sets

Set 1: dadel, datum, daling

Set 2: hamer, haring, hagel

Set 3: kilo, kiezel, kiwi

CVC-Sets

Set 4: haver, haven, havik

Set 5: kolen, colon, cola

Set 6: polo, polis, Polen

\section{Experiment 6}

CV-Sets

Set 1: boetiek, boerin, boeket

Set 2: koraal, kopie, kozak

Set 3: tomaat, toneel, totaal

CVC-Sets

Set 4: barak, baret, baron

Set 5: komijn, komiek, komeet

Set 6: tabel, taboe, tabak

Experiments 7 and 8

C-Sets (tested in Experiment 7)

Set 1: polder, pinda, panter

Set 2: sekte, singel, sultan

Set 3: tempo, turner, tarwe

CV-Sets (tested in Experiments 7 and 8)

Set 4: deksel, delta, denker

Set 5: campus, kansel, cactus

Set 6: sambal, sanctie, saldo

CVC-Sets (tested in Experiment 8)

Set 4: halte, halter, halma

Set 5: kervel, kermis, kerker

Set 6: morgen, mormel, mortel

Note. A listing of the materials including the prompts and an English translation of the word pairs can be provided by the author.

\section{REFERENCES}

ABd-El JaWad, H., \& ABU-Salim, I. (1987). Slips of the tongue in Arabic and their theoretical implications. Language Sciences, 9, 145-171.

Boou, G. E. (1981). Generatieve fonologie van het Nederlands [Generative phonology of Dutch]. Utrecht: Spectrum.

Boomer, D. S., \& LAver, J. D. M. (1968). Slips of the tongue. British Journal of Disorders of Communication, 3, 2-12.

DELL, G. S. (1984). Representation of serial order in speech: Evidence from the repeated phoneme effect in speech errors. Journal of Experimental Psychology: Learning, Memory, and Cognition, 10, 222-233.

Dell, G. S. (1986). A spreading activation theory of retrieval in sentence production. Psychological Review, 93, 283-321.

DeLl G. S. (1988). The retrieval of phonological forms in production: Tests of predictions from a connec- 
tionist model. Journal of Memory and Language, 27, 124-142.

FromkIN, V. A. (1971). The non-anomalous nature of anomalous utterances. Language, 47, 27-52.

Fromkin, V. A. (Ed.). (1973). Speech errors as linguistic evidence. The Hague: Mouton.

FUdGE, E. C. (1969). Syllables. Journal of Linguistics, 5, 253-286.

GARRETT, M. F. (1975). The analysis of sentence production. Advances in research and theory. In G. H. Bower (Ed.), The psychology of learning and motivation (Vol. 9, pp. 133-177). New York: Academic Press.

GARRETT, M. F. (1980). Levels of processing in sentence production. In B. Butterworth (Ed.), Language production: Vol 1. Speech and talk (pp. 177-220). New York: Academic Press.

Garrett, M. F. (1982). Production of speech: Observations from normal and pathological language use. In A. Ellis (Ed.), Normality and pathology in cognitive functions (pp. 19-76). London: Academic Press.

Goldsmith, J. (1976). An overview of autosegmental phonology. Linguistic Analysis, 2, 23-68.

Halle, M., \& Vergnaud, J.-R. (1980). Three dimensional phonology. Journal of Linguistic Research, 1, 83-105.

HAYES, B. (1981). A metrical theory of stress rules. Bloomington, IN: Indiana University Linguistics Club.

HULST, H. VAN DER (1984). Syllable structure and stress in Dutch. Dordrecht: Foris.

HYMAN, L. M. (1985). A theory of phonological weight. Dordrecht: Foris.

KAHN, D. (1976). Syllable-based generalizations in English phonology. Doctoral dissertation, Massachusetts Institute of Technology, Cambridge, MA.

LEVELT, W. J. M. (1989). Speaking: From intention to articulation. Cambridge, MA: MIT Press.

MaCKaY, D. G. (1970). Spoonerisms: The structure of errors in the serial order of speech. Neuropsychologia, 8, 323-350.

MACKAY, D. G. (1972). The structure of words and syllables: Evidence from errors in speech. Cognitive Psychology, 3, 210-227.

MACKAY, D. G. (1987). The organization of perception and action. A theory for language and other cognitive skills. New York: Springer-Verlag.

Meyer, A. S. (1990). The time course of phonological encoding in language production: The encoding of successive syllables of a word. Journal of Memory and Language, 29, 524-545.

NesPOR, M., \& VoGEL, I. (1986). Prosodic phonology. Dordrecht: Foris.

Noотевоом, S. G. (1969). The tongue slips into patterns. In A. G. Sciarone, A. J. van Essen, \& A. A. van Raad (Eds.), Nomen: Leyden studies in linguistics and phonetics (pp. 114-132). The Hague: Mouton.

Selkirk, E. (1984). On the major class features and syllable theory. In M. Aronoff \& R. T. Oehrle (Eds.), Language sound structure. Cambridge, MA: MIT Press.

Shattuck-Hufnagel, S. (1979). Speech errors as evidence for a serial-ordering mechanism in sentence production. In W. E. Cooper \& E. C. T. Walker (Eds.), Sentence processing: Psycholinguistic studies presented to Merrill Garrett (pp. 295-342). Hillsdale, NJ: Erlbaum.

Shattuck-HufNagel, S. (1983). Sublexical units and suprasegmental structure in speech production planning. In P. F. MacNeilage (Ed.), The production of speech (pp. 109-136). New York: SpringerVerlag.

Shattuck-Hufnagel, S. (1986). The representation of phonological information during speech production planning: Evidence from vowel errors in spontaneous speech. In C. J. Ewens \& J. M. Anderson (Eds.), Phonology yearbook (Vol. 3, pp. 117-149). Cambridge, UK: Cambridge University Press.

Shattuck-HufNagel, S. (1987). The role of wordonset consonants in speech production planning: New evidence from speech crror patterns. In $\mathrm{E}$. Keller \& M. Gopnik (Eds.), Motor and sensory processes of language (pp. 17-51). Hillsdale, $\mathrm{NJ}$ : Erlbaum.

Stemberger, J. P. (1983a). Speech errors and theoretical phonology: A review. Bloomington, IN: Indiana University Linguistics Club.

Stemberger, J. P. (1983b). The nature of $/ \mathrm{r} /$ and $/ \mathrm{l} / \mathrm{in}$ English: Evidence from speech errors. Journal of Phonetics, 11, 139-147.

Treiman, R. (1984). On the status of final consonant clusters in English syllables. Journal of Verbal Learning and Verbal Behavior, 23, 343-356.

(Received January 8, 1990)

(Revision received May 15, 1990) 